\title{
ESPACIOS PÚBLICOS ¿BIENES DE CONSUMO? Relaciones conceptuales entre tecnologías digitales e imaginarios urbanos
}

\author{
P. Sebastián Cortez Oviedo \\ Institución a la que pertenece: INVIHAB-CEUR CONICET / FAUD-UNC \\ Directora de investigación: Prof. Ana Falú \\ pcortezoviedo@gmail.com
}

\begin{abstract}
RESUMEN
El trabajo presenta una discusión teórica acerca de los principales procesos y dinámicas del orden digital referidos al hábitat de lo urbano, en particular aquellos relacionados a los espacios públicos, a partir del desarrollo de un análisis crítico de las posibles relaciones entre tecnologías digitales -entendidas desde las narrativas transmedia- e imaginarios urbanos. Estas relaciones se abordan desde la caracterización de los dispositivos Tecno-Culturales TIC como intermediarios en las experiencias estéticas de lo urbano, particularmente en el acceso, usos y apropiaciones de lo público. Estos lugares, como resultado de múltiples procesos simbólicos-culturales habrían modificado su valor de uso por un valor de cambio, cuyos imaginarios comunicados estarían convirtiendo estos espacios en mercancía de una creciente sociedad de consumo. En tal sentido y partir de este ensayo, se pretende promover un debate transdisciplinar en el campo del urbanismo acerca de los aspectos culturales de la Sociedad de la Información y el Conocimiento, particularmente aquel referido a (re)pensar las categorías de análisis que atraviesan este paradigma.
\end{abstract}

Palabras clave: Espacios públicos - Imaginarios urbanos - Orden digital

\begin{abstract}
This piece of research presents a discussion on the main processes and dynamics of the digital order referred to the urban habitat, in particular those related to public spaces, from the development of a critical analysis to the possible relationships between digital technologies - understood from the transmedia storytelling- and urban imaginaries. These relationships are addressed from the characterization of ICT Techno-Cultural Dispositive as intermediaries in the aesthetic experiences of the urban spaces, particularly in the access, uses and appropriations of the public spaces. These places, as result of multiple symbolic-cultural processes, would have modified their use value for a value of change, whose imaginary communicated would be turning these spaces into merchandise of a growing consumer society. In this sense and from this paper, it is intended to promote a transdisciplinary debate in the field of urbanism about the cultural aspects of the Information and Knowledge Society, particularly that referred to (re) think the categories of analysis that cross this paradigm.
\end{abstract}

Keywords: Public Spaces - Urban Imaginaries- digital order 


\section{INTRODUCCIÓN}

Cuando encendemos un smartphone, una portátil o la misma televisión, nuestra realidad parece interconectarse a través de una nueva dimensión que rara vez podríamos distinguir sus límites. Esta dimensión comunicacional complementa, de alguna manera, nuestras propias cotidianeidades y nos constituye en muchos sentidos como sujetos.

Este orden digital que llegó para quedarse a mediados de los '90, ha recibido por sus teóricos distintos enunciados: Pos-industrialización (Bell, 1973), Sociedad de la información (Masuda,1980. Castells, 1997) Sociedad del Conocimiento (UNESCO, 2005); en definitiva, diferentes nombres para un mismo fenómeno socio-económico-político -y en un sentido más profundo, simbólico-, que continua modificando el hábitat de lo urbano a partir de incidir fuertemente en los mecanismos de producción y tecnologización de la sociedad y sus prácticas culturales.

Estas caracterizaciones, que serán desarrolladas más adelante, pueden sintetizarse en lo que Finquelievich (2016) denomina Revolución Comunicacional, una sociedad de innovación y cambios productivos vinculados a las TIC. Procesos socio-culturales que no solo han modificado dimensiones productivos y territoriales, sino también nuestra manera de inter-relacionarnos con nuestras espacialidades.

El espacio, tiempo y limite pueden ser considerados nociones fundantes de nuestro campo disciplinar, sin embargo, a partir del paradigma de la Sociedad de la Información y el Conocimiento (SIC) han modificado sus constantes conceptuales y empíricas. Nuestra percepción del territorio, de la ciudad en particular, y de nuestros modos de dimensionar el espacio-tiempo cambian al son de las nuevos dispositivos tecno-culturales.

Las nuevas tecnologías digitales están presentes en lo cotidiano de nuestras vidas, desde aspectos sensibles y visibles hasta subjetivos y complejos, que no siempre racionalizamos y que se expresan en nuestras prácticas sociales. Los espacios públicos son el lugar de esas prácticas. Tanto físicos como virtuales, representan el escenario de lo social, en particular -y que interesa analizar-, el lugar del intercambio cultural.

El debate en torno a los espacios públicos constituye una discusión central del paradigma de la SIC, ya que los cambios en las matrices productivas, territoriales y demográficas continúan generando segregación sociourbana, conflictos y violencias que instituyen estos espacios como el lugar de su expresión. Asimismo, las nuevas lógicas económico-comunicacionales de la SIC, en particular las narrativas transmedias, y una creciente penetración de las tecnologías digitales en relación a la (con)vivencia de lo urbano, hacen necesaria una caracterización a partir de un debate conceptual de aproximación.

Una aproximación que este trabajo desarrollará a partir de un análisis crítico-bibliográfico, recuperando en diálogo las principales discusiones planteadas por autores referentes al paradigma de la SIC. Estas discusiones forman parte de los resultados conceptuales preliminares de mi tesis doctoral, la cual aborda la problemática del rol de las TIC en las dinámicas de acceso, usos y apropiaciones de los espacios públicos.

Este trabajo tiene características de ensayo, y pretende desde ese lugar aportar al debate transdisciplinar dentro del urbanismo, en torno a la discusión que suscitan los espacios públicos y sus debates actuales. En particular, aportar una caracterización de los mecanismos de mercantilización del espacio y de sus vivencias, entendidas como experiencias estéticas y resultado del consumo de tecnologías digitales y las nuevas lógicas económicas en ellas implícitas.

Por último, el ensayo se estructura a partir de los apartados siguientes: 2- Relaciones primarias: comprende el plateo de discusiones introductorias sobre la SIC e inquietudes frente a tres abordajes que para este trabajo son principales en la argumentación de sentido: Tiempo-Espacio y Ciudad, Dispositivo y Orden Digital, e Identidades e Imaginarios. 3 - Los espacios públicos como mercancía: se plantea en este apartado la discusión central del trabajo a partir de dos aproximaciones: ¿De qué manera se expresa este fenómeno social en los espacios públicos bajo el orden digital SIC? Y ¿Desde qué instrumentos semióticos, lógicas y objetivos aparentes? Desde ellas indagar acerca de la injerencia de los conceptos de experiencia estética y las narrativas transmedia en los posibles procesos de mercantilización de los espacios públicos; por último, 4- Hacia futuros debates: a modo de conclusiones abiertas e intensiones del ensayo respecto a los desafíos disciplinares. 


\section{RELACIONES PRIMARIAS}

En función de delimitar un horizonte conceptual de referencia al tema, este apartado desarrollará breves discusiones en torno a las dinámicas socio-territoriales del paradigma social actual. En particular, aquellas referidas a caracterizar algunos de sus procesos culturales que se vinculan con los espacios públicos a partir de la intermediación de nuevas tecnologías del orden digital y sus subjetividades.

Antes de profundizar en los apartados propuestos, es preciso explicitar de manera sintética algunas referencias en torno al paradigma socio-económico que hoy denominamos Sociedad de la Información y el Conocimiento (SIC). Término que, a lo largo de tres décadas, se complejizó a partir de los aportes teóricos de Peter Drucker, Daniel Bell, Yoneji Masuda, Manuel Castells entre otros, y que reconoce como referentes locales a Susana Finquelievich y Ester Schiavo en los abordajes urbanos.

Si bien todos estos autores han referido a este paradigma con nominaciones diferentes -el término SIC fue consagrado por las conferencias UNESCO's Natural Sciences Sector (2003) y por el informe "Hacia las sociedades del conocimiento" (UNESCO, 2005)-, ellos comparten la visión de un proceso económico y cultural auto-regenerativo basado en cambios de lógicas de producción industrial a una de servicios, sustentados por una estructura comunicacional y tecnológica, siendo 'lo digital' su expresión más concreta. Estos cambios de matriz productiva generaron un fuerte impacto ambiental en los territorios, particularmente el urbano, con profundas tensiones socio-territoriales que constituyen hoy una de las problemáticas más sensibles del campo disciplinar urbano. Tensiones que se expresan como conflictos multi-dimensionales físicos, culturales, económicos y fundamentalmente simbólicos- tales como el aumento de poblaciones y densidades urbanas, migraciones, segregación social, fragmentación urbana, acceso al suelo, déficit habitacional, violencias y exclusiones, huella ecológica, contaminación, acceso a las infraestructuras, etc.

Estas problemáticas, complejas y simultáneas, imprimen en el paradigma de la SIC una impronta de mercantilización de sus procesos socio-culturales que suplantan, en términos marxistas, el valor de uso por el valor de cambio. Es decir, son varios los derechos sociales que tenderían a convertirse en bienes de consumo de una sociedad cada vez más (de)pendiente de las dinámicas del mercado. Tal es el caso de la vivienda y la problemática de su derecho y acceso, los espacios públicos como plataformas de construcción identitaria que pone en discusión sus lógicas de control y acceso, y hasta la misma ciudad con los procesos de turistificación y las tensiones urbanas que ello suscita. En este punto es donde podríamos preguntarnos acerca de qué manera incide la información y el conocimiento en estos procesos, refiero a las tecnologías digitales y los imaginarios urbanos, y cuál es el rol de los dispositivos tecno-culturales TIC en esta interacción cultural, que al decir de Finquelievich (2016) sobre las TIC, constituyen instrumentos conceptuales e ideológicos de este paradigma socio-económico.

Los procesos culturales de la SIC son extensos y cruzan de manera trasversal nuestras sociedades adquiriendo particulares dinámicas y lógicas en todo el globo, pero todas estas expresiones comparten una estrecha relación con lo comunicacional (Castells, 2009) cuya incidencia en lo socio-territorial tiende a intensificarse con su desarrollo en el tiempo, lo que presenta el desafío de acotar lo efímero para su abordaje. Particularmente este ensayo busca con esta discusión teórica generar un marco conceptual sobre los procesos que este paradigma socio-económico le incide a los espacios públicos y su creciente mercantilización, a partir del consumo de dispositivos tecno-culturales TIC que tienen a la imagen técnica como mercancía central en la construcción de nuevas experiencias estéticas que constituyan y reafirmen las identidades de los sujetos, y que alteran nociones básicas como espacio-tiempo e incluyen otras nuevas como procesos de construcción de imaginarios en la (con)formación de un orden digital.

Estas nuevas lógicas generadas por una hiper-conexión creciente pone en debate la manera en que desde nuestro campo disciplinar, el urbanismo y la arquitectura, objetivamos y construimos nuestros abordajes y categorías que han sido a lo largo de estos últimos 70 años inmutables. Por ello, este ensayo prefiere no encuadrar esta discusión como una problemática 'pos-moderna de los espacios públicos', por entender que esta categoría -agotada por fuera de las tradiciones y lo genérico- no resultaría, en términos epistémicos y hasta ontológicos (Latour, 2007), la más adecuada en las interpretaciones de los procesos de la SIC, o de lo que comúnmente se suele denominar 'contemporaneidad'.

En este sentido, los apartados siguientes estarán orientados a incorporar posicionamientos teóricos de abordaje en diferentes aproximaciones de sentido al tema. Estas inquietudes serán articuladas en tres apartados que refieren a los núcleos que este trabajo considera relevantes, comenzando por indagar acerca 
de cómo el paradigma de la SIC y su tecno-cultura inciden en las nociones de Tiempo-Espacio y Ciudad; continuando con un debate acerca de los presupuestos en torno a Dispositivo y Orden digital; y por último, un debate sobre los procesos de construcción de Identidad e Imaginarios en relación a los espacios públicos y a partir de lo comunicacional.

\subsection{DE TIEMPO, ESPACIO Y CIUDAD}

Es preciso complejizar el debate acerca del paradigma de la SIC desde las nociones de tiempo, espacio y límite, en particular aquellas características conceptuales, territoriales y culturales en relación a la ciudad. Al respecto, Castells, uno de sus principales teóricos, sostiene:

Una nueva sociedad surge siempre y cuando pueda observarse una transformación estructural de las relaciones de producción, en las relaciones de poder y en las relaciones de experiencia. Estas transformaciones conllevan una modificación igualmente sustancial de las formas sociales del espacio y el tiempo, y la aparición de una nueva cultura. (Castells, 1997: p.374)

Como sostuve en la introducción, dos categorías inherentes a nuestro campo disciplinar como lo son espacio y tiempo se ven modificadas por la aparición de nuevas tecnologías y sus aplicabilidades. No solamente desde sus concepciones ontológicas sino prácticas. El tiempo-espacio ya no significa lo mismo que en la sociedad industrial, se ha superado su idea de constante, habitamos un tiempo atemporal (Castells, 1997). El espacio se diluye en las nuevas conexiones comunicacionales promovidas y producidas por las Tecnologías de la Información y Comunicación (TIC), que han hecho del mundo -en particular de nuestras ciudades- una multidimensión espacio-comunicacional. En este sentido, Bauman (2013:134) al respecto de esta realidad indeterminada, de límites, tiempos y espacios difusos, expresa: "La instantaneidad (anular la resistencia del espacio y 'licuificar' la materialidad de los objetos) hace que cada momento parezca infinitamente espacioso, y la capacidad infinita significa que no hay límites para lo que puede extraerse de un momento... por breve y fugaz que sea". Los cambios en las nociones de tiempo-espacio-limite _inducidas por una tecno-cultura- inciden fuertemente en nuestras (con)vivencias espaciales, haciendo necesaria una reflexión acerca de conceptos como ciudad y territorio.

Los aspectos culturales de la SIC -en particular los socio-productivos-, modifican no solo categorías sino también cosmovisiones, que se pueden evidenciar en el análisis de las dinámicas territoriales de la ciudad. Según Fernández (2014), "[...] para comprender los procesos urbanos actuales es necesario retomar el concepto de cito-geografía, toda ciudad debe ser pensada desde el punto de vista de la experiencia y no desde la forma". Tal lo cual, resulta clave plantearnos un análisis cualitativo sobre como esta experiencia se articula y se expresa, en particular interesa aquella ligada a la experiencia de lo público y que será desarrollada en el apartado tres.

Continuando con el debate acerca de la ciudad bajo el paradigma social actual, Susana Finquelievich nos platea el desafío de pensarla como red, que no solo representa interconexiones espaciales sino también temporales. En su decir:

En la Sociedad la Información, ¿Qué es el territorio urbano? Por lo pronto, excede los límites de lo que se conocía como "lo local" [...] Cuando se chatea con amigos que viven en diferentes lugares del globo, cuando se compran bienes y servicios por internet, cuando se establecen relaciones afectivas con personas que bien en cualquier parte del globo, encontradas en el ciberespacio, ¿En que ciudad se está? En ninguna y todas, en un nuevo modelo para armar; en resumen, en el ciberespacio. (Finquelievich, 2000: pp. 106-107)

Estas observaciones son interpretadas por Borja \& Castells (1998:12) en lo que denominan como "el declive histórico de las ciudades", ciertamente hablando desde su concepción tradicional y material. En su decir: "[...] la globalización, la informalización y la difusión urbana generalizada parecen converger hacia la desaparición de la ciudad como forma específica de relación entre territorio y sociedad."

A partir de lo expuesto hasta aquí, podemos acordar que la ciudad ha dejado de ser aquella entidad física para constituirse en una construcción semiótica, de profusos límites que llegan incluso hasta lo intangible, producto de lo digital y lo comunicacional, expresiones per se del paradigma la SIC. Estos cambios en la manera de construir, habitar y pensar ciudad, producidos mayormente por modificaciones en las nociones de tiempo-espacio y limite, han generado una nueva dimensión urbano-vivencial de los sujetos. Esta nueva 
dimensión -más compleja que las categorías plateadas de real y virtual_ se constituye como la plataforma de socialización de la SIC, una suerte de meta-realidad que des-territorializa aspectos socio-urbanos que, valga la contradicción, se consideran territoriales para nuestro campo disciplinar. Es importante preguntarnos entonces de qué manera nuestro campo disciplinar se posiciona frente a este fenómeno, con que presupuestos y desde que debates disciplinares, ya que por lo pronto y dada su trayectoria tenderá a profundizarse y complejizarse en el corto plazo, haciendo de la SIC un paradigma auto-regenerativo a partir de sus dispositivos tecno-culturales TIC y sus álgidos avances en materia de tecnologias digitales.

\subsection{DE DISPOSITIVO Y ORDEN DIGITAL}

Cuando pensamos una definición de dispositivo encontramos que, como sucede con el concepto de espacio público, sus límites se difuminan y resulta, por lo pronto, necesaria una delimitación de campo. En términos generales según la RAE, un dispositivo es un mecanismo o artificio para producir una acción prevista, algo que dispone. Esta definición, elemental, nos aproxima a dos cuestiones que iremos complejizando, la primera referida a un aspecto tangible de 'la cosa', y la segunda, a sus relaciones subjetivas.

En pos de introducirnos a esta discusión, recupero los aportes planteados por Michel Foucault ante tres dimensiones considerables del dispositivo, referimos a su sentido de red, además del de naturaleza y acontecimiento. En su decir:

Lo que trato de situar bajo ese nombre es, en primer lugar, un conjunto decididamente heterogéneo, que comprende discursos, instituciones, instalaciones arquitectónicas, decisiones reglamentarias, leyes, medidas administrativas, enunciados científicos, proposiciones filosóficas, morales, filantrópicas; en resumen, los elementos del dispositivo pertenecen tanto a lo dicho como lo no-dicho. El dispositivo es la red que puede establecerse entre estos elementos. (Foucault, 1984: p.127)

Complementando esta aproximación conceptual, García Fanlo (2011:2) desde su lectura de Foucault, sostiene: "Los dispositivos constituirían a los sujetos inscribiendo en sus cuerpos un modo y una forma de ser". Tal lo cual y a partir de lo expuesto, podemos delimitar para este ensayo que un dispositivo es un mecanismo social que se expresa a partir de relaciones de poder, es decir, el poder de instrumentalizar la cultura a partir de los mismos, una estructura que moldea y da forma a las subjetividades que agencian los procesos sociales, por dentro y fuera del espacio físico.

El concepto de orden digital plateado en la introducción, es el nombre con que denomino al macro dispositivo que instrumentaliza las construcciones de sentido dentro del paradigma de la SIC. Puede considerarse una cosmovisión que da sentido a su expresión más acabada, lo digital, haciendo de ella una dinámica semántica, tecnológica y cultural que atraviesan los estrados sociales y territoriales de manera disímil pero contundente, incidiendo fuertemente en la (con)vivencia de sus prosumidores, particularmente en lo urbano. Se expresa en el territorio de diversas maneras, desde la regulación y administración de las infraestructuras urbanas en las llamadas zonas inteligentes _-smart cities_ hasta la intermediación de las prácticas colectivas e individuales de los sujetos. Así, el orden digital se manifiesta socio-territorialmente no solo como una interface tecnológica, sino como plataforma de construcción de sentido e identidad territorial. Es en este punto que este macro dispositivo adquiere la escala que interesa para el análisis, aquella vinculada al uso y consumo de Tecnologías de la Información y Comunicación (TIC) en la institución de lo público como lugar.

En tal sentido, el acrónimo TIC no solo representa una definición en palabras, sino también de sentidos. Son instrumentos conceptuales e ideológicos de la SIC, y desde un análisis más profundo, una exclusa entre dos mundos, entre lo analógico y lo digital, conformando la denominada brecha digital. Una desigualdad no solo de acceso y conexión, sino social, que segmenta fuertemente las oportunidades de desarrollo de los sujetos al imposibilitarlos de integrar las dinámicas culturales y procesos productivos del orden digital de la SIC.

Este fenómeno queda evidenciado en los datos cuantitativos acerca de la conectividad digital en Argentina y la región. Según la Unión Internacional de Telecomunicaciones en su informe 2016, sostiene que Argentina es el país con mayor conexión a internet de los países latinoamericanos, superando incluso ciertos países europeos. Esto representa que un $70 \%$ de la población argentina accede a internet, lo que ubica al país en el puesto número 54 a nivel global. Asimismo, el informe destaca que solo el 55,52\% de los hogares argentinos tiene acceso a la red de banda ancha, apenas supera a Brasil con un 54,50\%; lo cual representa que casi el $50 \%$ de la población accede a internet a través de smartphones con el costo económico que esto conlleva. 
Esta desigualdad de acceso -entendida en términos de calidad- y una creciente demanda de los usos de estas tecnologías se expresa en el informe 2016 de la Comisión de la Banda Ancha para el Desarrollo Sostenible de las Naciones Unidas, donde destaca que el 55\% de la población mundial aún no posee acceso a internet.

Continuando con esta línea en torno al acceso y uso de internet del orden digital, CEPAL, en su informe Estado de la Banda Ancha en América Latina y el Caribe (2016), sostiene que existe una marcada desigualdad respecto al acceso a internet entre los países de la región. En Latinoamérica y el Caribe solo un $43,4 \%$ de su población tiene acceso a internet, mientras que el promedio de los países de la OCDE alcanza el $85 \%$. De los países analizados, Cuba, Haití y Nicaragua registran un acceso a internet menor al 15\% de su población, mientras que Argentina y Panamá superan el 60\%. En conclusión, de los 24 países miembros de la CEPAL, solo el $16,6 \%$ presenta más del $50 \%$ de su población con acceso a internet.

Según estas cifras, el acceso a las tecnologías digitales no es un proceso igualitario en el mundo y mucho menos en nuestra región. Tal lo cual, como sostuve en los párrafos anteriores, hacen de la brecha digital un problema social sensible de abordar bajo el paradigma de la SIC. En particular desde el urbanismo, ya que, desde un análisis prospectivo, la (con)vivencia de lo urbano, de la ciudad y de sus espacios públicos estarían cada vez más intermediadas por las TIC abriendo un nuevo debate acerca de sus derechos y accesos. Estas intermediaciones estarían relacionadas al consumo de la imagen, mercancía y lenguaje simbólico de los dispositivos tecno-culturales.

\subsection{DE IDENTIDADES E IMAGINARIOS}

La construcción de identidad de los sujetos tanto individual como colectiva es uno de los intercambios sociales de mayor visibilidad dentro de la SIC. En muchos sentidos posibilitado por la hiper-conexión y la comunicación de símbolos, particularmente la imagen técnica (Sontag, 2005), a partir de dispositivos tecno-culturales TIC como Instagram, YouTube, WhatsApp, Facebook, entre otros: conformando un nuevo régimen escópico (Jay, 2003). Es decir, una nueva manera de mirar y ser visto, dando sentido al intercambio de lo visual y coproduciendo dialécticamente nuevas identidades e imaginarios. Es por ello que abordaremos esta discusión comenzando por los aportes de Castells, que al respecto sostiene:

La identidad ha de distinguirse de lo que tradicionalmente los sociólogos han denominado roles y conjuntos de roles [...] se define por normas estructuradas por las instituciones y organizaciones de la sociedad. Su peso relativo para influir en la conducta de la gente depende de las negociaciones y acuerdos entre los individuos y esas instituciones y organizaciones. Las identidades son fuente de sentido para los propios actores y por ellos mismos son construidos mediante un proceso de individualización. (Castells, 1998: p.29)

Es preciso aclarar que las negociaciones y acuerdos plateados por el autor involucran la comunicación, particularmente la digital, por ello, aquí es donde las TIC intervendrían en su rol de dispositivo bajo la cosmovisión del orden digital articulando y dando sentido a estos intercambios. Estas construcciones a su vez se dan en un contexto marcado por relaciones de poder bajo tres formas (Castells, 1998:30): Identidad legitimadora, aquellas promovidas por las instituciones sociales y que se desarrollan bajo el presupuesto de una teoría de la autoridad y la dominación (Sennett, 2011); Identidad de resistencia, generada por los actores estigmatizados por las lógicas de la dominación y que se expresa en trincheras culturales de supervivencia; y por último, Identidad proyecto, cuando los sujetos construyen una identidad que redefine su posición en la sociedad buscando la transformación de toda la estructura social. Es en esta última, particularmente, donde la incidencia de los dispositivos tecno-culturales TIC se torna central, permitiendo traccionar construcciones individuales y colectivas con mayor sinergia tanto a nivel de las relaciones sociales como en sus expresiones físicas en el espacio de lo público, que lo constituyen como el lugar del intercambio identitario.

Estos intercambios se desarrollan a partir de significantes que construyen otros significantes (Žižek,1994). En tal sentido, podemos caracterizar los espacios públicos -y en función de dirigirnos a su debate- como un significante macro en dicho proceso, ya que al mismo tiempo que se lugarizan -símbolo- como lugar de lo público -signo- se constituyen en imaginarios del intercambio social urbano. Desde esta perspectiva, podemos argumentar y explicitar la relación existente entre tecnologías digitales e imaginarios urbanos.

Continuando con la discusión acerca de identidad y su relación con lo público como espacio, podemos sostener a partir de la aproximación de sentido antes expuesta, que los espacios públicos se habrían tornado 
proscenios de la exhibición urbana, articulando sentidos sociales y espaciales que potencian o minimizan la construcción identitaria de los sujetos. Estos espacios se habrían convertido en dispositivos sociales a partir de la comunicación y el consumo de sus imaginarios _donde la imagen técnica jugaría un rol fundante_, una influencia concreta del orden digital de la SIC.

En este sentido, podríamos reflexionar lo planteado por Žižek acerca de cierta autonomía de los sujetos de decidir aquellas relaciones simbólicas que construyen su identidad, en su decir:

Fuera de mis relaciones con los otros no soy nada. Soy solamente el conjunto de estas relaciones [...] pero esta misma "nada" es la nada de la pura relación consigo mismo: soy solamente lo que soy para los otros, y aunque simultáneamente soy aquel que se auto-determina como yo mismo, es decir, soy el que determina cual red de relaciones con los otros me va a determinar. (Žižek,1994)

Desde lo planteado por el autor y desde la perspectiva del ensayo, podemos delinear una reflexión final acerca de si los espacios públicos como dispositivos identitarios constituyen a los sujetos, o si los sujetos constituyen estos lugares a partir de su apropiación-expresión del espacio urbano. En este sentido, de qué manera las TIC devenidas en 'sujeto tecno-cultural' - esto plateado desde la teoría del actante rizoma que considera objetos y sujetos en igual relación dialéctica y simétrica (Latour, 2008)- inciden en el sentido de esa relación. Es decir, si la comunicación del imaginario de lo público da entidad a los espacios independientemente de las prácticas que los sujetos pudiesen realizar en ellos, y de ser así, de que manera las narrativas transmedias y las lógicas económicas de la SIC convertirían estos espacios en una mercancía, un producto más de una creciente sociedad de consumo.

\section{LOS ESPACIOS PÚBLICOS COMO MERCANCIA}

Los debates actuales acerca de los procesos culturales de la SIC y su caracterización en relación al hábitat de lo urbano son complejos, y recuperando lo desarrollado anteriormente, podemos sostener que se trata de procesos diversos y solapados con diferentes lecturas, incluso por dentro de la misma perspectiva socioantropológica plateada. La revolución comunicacional explicita de la SIC seria irreversible cuyas dinámicas parecen acelerase con su desarrollo en el tiempo, donde cualquier intento por encuadrar estos procesos presenta un desafío epistémico y hasta ontológico. El orden digital de la SIC no solo plantea nuevas delimitaciones y miradas en torno a los debates de ciudad y territorio, o sobre nociones de tiempo-espacio y limite sino, en un sentido más profundo, nuevos debates disciplinares en torno a sus procesos socio-culturales que terminarían por dar sentido a nuestras prácticas proyectuales. Tal lo cual y desde este posicionamiento, se enmarca el debate siguiente en torno a los espacios públicos como mercancía, es decir, de qué manera sus lógicas de apropiación, usos y acceso se ven influenciadas por tendencias de mercado, habilitando, modificando y construyendo nuevos imaginarios de lo público.

Es preciso comenzar por una definición del concepto de espacio público para este trabajo, que tiene que ver no solo con la reinterpretación del espacio libre planteado por el CIAM y devenido en espacio verde, sino con una red de relaciones sociales que operan en el territorio y que articula o, mejor dicho, instituye el lugar del intercambio público. Estos lugares se expresan a partir de cuatro dimensiones iniciales, lo público en lo social, lo público en lo físico-espacial, lo público en lo legal, y lo público en lo simbólico. Interesa esta última dimensión, la simbólica, ya que tranversaliza las anteriores convirtiéndolo en un dispositivo social, y donde se estarían propiciando nuevas construcciones de sentido a partir del orden digital.

Es preciso recuperar algunas discusiones teóricas propuestas por autores especializados en el tema -tanto del campo del urbanismo como de la antropología social-, y que son necesarias de articular entre sí. En este sentido, Borja (2014) sostiene: "La urbanística debe considerar el espacio público como base estructural de la ciudad, el factor ordenador principal que determine su entorno, la calidad ambiental, su imagen y accesibilidad". A partir de esta definición y desde el enfoque del trabajo, se propone la siguiente reflexión: si los espacios públicos son base de la ciudad determinando incluso su accesibilidad, es decir, su derecho (Harvey, 2008), cuanto más importante aún es pensar acerca de los procesos de mercantilización del espacio público en términos conceptuales y también empíricos. En este sentido, vale un análisis crítico acerca de cómo y desde que posicionamiento epistémico el urbanismo interpelará este fenómeno. 
Continuando con esta conceptualización, se recupera lo planteado por Burgess (2009) que en su decir sostiene que existen tantas expresiones de lo público como fragmentos sociales coexistan en un mismo territorio. Por eso, este trabajo los expresa en plural, y por menor que sea la intención resulta un cambio de enfoque. Asimismo, en esta línea, se enmarca la conceptualización de Manuel Delgado, que sostiene al respecto de la relación entre lo social y estos espacios, lo siguiente:

A ese espacio público como categoría política que organiza la vida social y la configura políticamente le urge verse ratificado como lugar, sitio, comarca o zona, en que sus contenidos abstractos abandonen la superestructura en la que estaban instalados y bajen literalmente a la tierra, se hagan, por así decirlo, "carne entre nosotros". [...] El espacio público es una de aquellas nociones que exige ver cumplida la realidad que evoca y que en un cierto modo también invoca, una ficción nominal concebida para inducir a pensar y a actuar de cierta manera y que urge verse instituida como realidad objetiva. (Delgado, 2015: p.38)

Estas palabras nos introducen hacia la discusión central planteada por este ensayo, acerca de si los espacios público producto de las lógicas comerciales del orden digital SIC y a través de los dispositivos tecno-culturales TIC, habrían modificado su valor de uso por un valor de cambio, convirtiéndose en una mercancía necesaria en los procesos de construcción identitaria de los sujetos.

En tal sentido, interesa el pensamiento de Delgado en relación a que los espacios públicos constituyen un dispositivo social capaz de organizar -o direccionar- las relaciones sociales, y adscribiendo a este planteo surgen dos aproximaciones: ¿De qué manera se expresa este fenómeno social en los espacios públicos bajo el orden digital SIC? y ¿Desde qué instrumentos semióticos, lógicas y objetivos aparentes?

Con respecto a la primera reflexión, se puede sostener que a partir de la penetración mediática posibilitada y co-producida del orden digital SIC, los espacios públicos -o mejor dicho, lo que Habermas (2005) da en llamar publicidades (esferas públicas burguesas)-, han complejizado su rol social. Esta dinámica se explica, de cierta manera, a partir de la caracterización de la sociedad del espectáculo propuesta por Guy Debord, quien sostiene que "Todo lo que antes era vívido se ha alejado en una representación" (Debord,1995:8). Vale aclarar que, si bien el autor se posiciona desde una perspectiva situacionista y tratando de caracterizar otro periodo histórico, y ciertamente otro paradigma social, su propuesta teórica no solo no ha cambiado durante el orden digital SIC, sino que se vio verificada y profundizada a partir del consumo de la imagen técnica y de la comunicación digital-.

Esta complejización de los roles de lo público en los espacios, entendidos como el signo que lugariza en la ciudad los intercambios sociales, habría modificado las nociones de accesibilidad, limites, usos y apropiaciones de estos espacios. Los espacios públicos desde sus dimensiones simbólicas se habrían convertido en un espectáculo. Un proscenio, en términos planteados por Delgado. En su decir:

[...] limitaría a identificar el espacio publico como espacio de visibilidad generalizada, en la que los co-presentes forma una sociedad, por así decirlo, óptica, en la medida en cada una de sus acciones está sometida a la consideración de los demás, territorio por tanto de exposición, en el doble sentido de exhibición y de riesgo. (Delgado, 2015: p.29)

En este sentido, y continuando con lo planteado por Debord y desde una lectura de Marx sobre el rol de la mercancía en los procesos de espectacularización de los intercambios, el autor, en su decir, sostiene:

Es el principio del fetichismo de la mercancía, es la dominación de la sociedad a través de "cosas suprasensibles, aunque sensibles" lo que se hace absolutamente efectivo en el espectáculo, en donde el mundo sensible se encuentra reemplazado por una selección de imágenes que existe por encima de él y que al mismo tiempo se ha hecho reconocer como lo sensible por excelencia. (Debord, 1995: p.21)

Para cerrar esta primera aproximación tendiente a reflexionar acerca de cómo se expresan los espacios públicos en el orden digital SIC, podemos sostener que, como dispositivos sociales estos espacios se ven atravesados por los procesos de una sociedad de consumo. A su vez, estas lógicas se expresarían en una marketinización de sus dimensiones físico-espaciales a partir de modelos consagrados en imaginarios urbanos -dimensión simbólica-, co-producidos por el consumo y el intercambio comunicacional de la imagen técnica y posibilitado por los dispositivos tecno-culturales TIC. En este sentido, y como relectura sobre la (con)vivencia de lo público, podemos completar esta postura con el decir de Debord (1995:9): "El espectáculo no es una colección de imágenes, sino una relación social entre personas mediada por imágenes". 
En cuanto a la segunda aproximación, acerca de qué instrumentos semióticos constituirían los espacios públicos del orden digital SIC, podemos hacer mención a dos conceptos: el primero, la experiencia estética, concepto que, a partir de los aportes de Benjamín (2003) sobre estética y su concepto de aura y los de Rancière (2014) sobre lo estético como categoría política, fue complejizado y adecuado a mi línea de investigación durante la tesis doctoral y publicado en trabajos previos; el segundo, las narrativas transmedia (Jenkins, 2003), relacionado a la mercantilización de productos que incluyen lo comunicacional como parte de central de ese proceso. A continuación, una definición breve de estos conceptos a partir de un trabajo previo que los articula en similitud conceptual a este ensayo:

La experiencia estética se define como una relación dialéctica-comunicacional entre sujeto-objeto. Esta incide en los modos y las formas en que experimentamos el espacio [...] es un discurso de deseo capaz de instituir lugares a partir del 'mensaje' producido y comunicado, [...] y se basa en la experiencia práctica-simbólica de la estética de Rancière como categoría política que define lugares, como la división o redistribución de lo sensible. (Cortez Oviedo, 2018: p.26)

Las narrativas transmedia [...] permitieron ampliar la idea del usuario unidimensional al concepto de prosumidor multidimensional. Esto se refleja en distintos consumos culturales que se valen de diversos medios y plataformas para comunicar una experiencia de deseo, donde el prosumidor es su consumidor y comunicador [...] Experimentamos un relato segmentado. Un mundo (co)creado que aprovecha la inteligencia colectiva de los prosumidores, generando un rizoma consumible que no solo se expande y se expresa desde plataformas digitales, gráficas, cinematográficas o históricas, sino -y recientemente por la realidad aumentada-, también a partir de lo urbano. (Cortez Oviedo, 2018: p.25)

Desde lo expuesto, la experiencia estética tendría un rol central en la consagración simbólica de los imaginarios urbanos de lo público. Comunicados desde dispositivos tecno-culturales TIC expresarían el discurso de deseo que mercantiliza su acceso, uso y apropiación, pudiendo institucionalizar lo público en cualquier lugar físico o virtual a partir del control de ese imaginario. Esta experiencia estética se vale de distintas herramientas comunicacionales para co-producirse y co-comunicarse, pero una de las más eficientes en relación a la dimensiones física-espaciales y simbólicas son las narrativas transmedia, que como sostiene Jenkins (2003:45) "Nos han convertido en cazadores y recolectores de información, asistimos a un proceso de convergencia mediática que hace que la suma del todo sea mayor a la suma de las partes. Experimentamos un relato segmentado".

Este relato segmentado del que habla el autor puede verificarse en distintos fenómenos que utilizan la lógica de las narrativas transmedias en la construcción de una experiencia estética de lo público. Por ejemplo, el caso de la tendencia glocal Pokemon Go, un juego que utiliza una plataforma geolocalizada que articula el espacio público como su escenario principal, pudiendo sus algoritmos modificar conductas, recorridos, permanencias y apropiaciones de sus prosumidores. Otro caso reciente, es la estrategia de Nike denominada House of Go, consistente en la instalación de una 'casa inteligente' en zonas donde se practica el running a modo tal de aumentar la experiencia (estética) deportiva a partir de dispositivos digitales y eventos streaming. Al mismo tiempo que sus prosumidores hacen uso de los productos de la marca, una experiencia transmediática que se implementó en Buenos Aires y en Ciudad de México durante marzo de 2018.

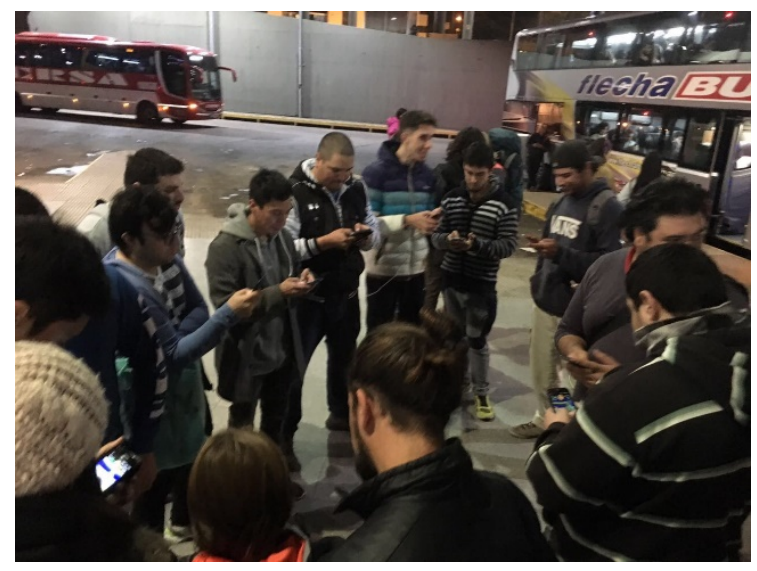

Figura 1. Típica práctica de juego Pokémon Go en

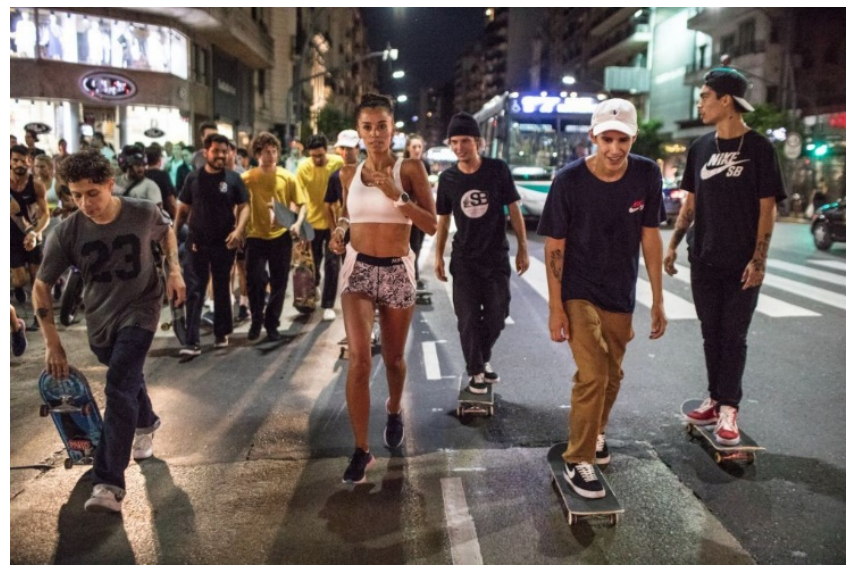

Figura 2. Evento House of Go NIKE, en las calles de Buenos

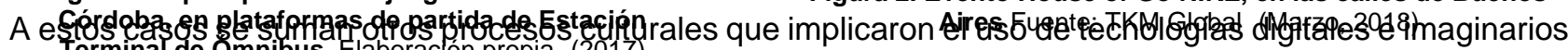
urbanos, como elMhovimiento Indignalias en Europa y Ocuppy Wall Street, ambos de 2011, cuyas expresiones 
sociales se hicieron eco en varias ciudades del mundo, aun sin compartir entre si los contextos políticos. Paralelamente y motivado por otras dinámicas geopolíticas que se extienden hasta nuestros días, la denominada "Primavera" árabe representó también una visibilización concreta de segmentación de la opinión pública en función de un interés supuesto y común, que instituyó los espacios públicos como su proscenio comunicado y legitimador, por dentro y fuera de los países involucrados. Procesos culturales que hicieron de lo comunicacional, particularmente del poder del hashtag y las redes sociales, una condición sine qua non, conformándolas en espacios del intercambio y extensión de lo público. Tales dinámicas instituyeron a los espacios públicos como redes tecno-culturales, cuyas reproducciones físico-espaciales se esparcieron por el globo sin distinguir contextos políticos ni socio-económicos, solo la 'necesidad' (comunicacional) de expresarse y constituirse como sujetos glocales de una tendencia global y trans-mediática, constituyendo así estos espacios como plataformas del consumo social y mediático.

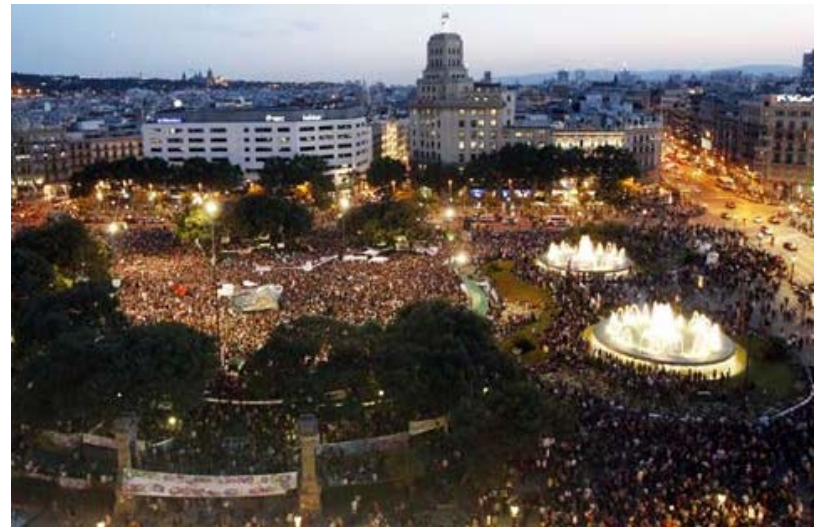

Figura 3. Plaza de Catalunya, el movimiento indignado en su primera semana, mayo 2011. Fuente: Diario El Mundo. $\mathrm{Ph}$ Quique García (2011)

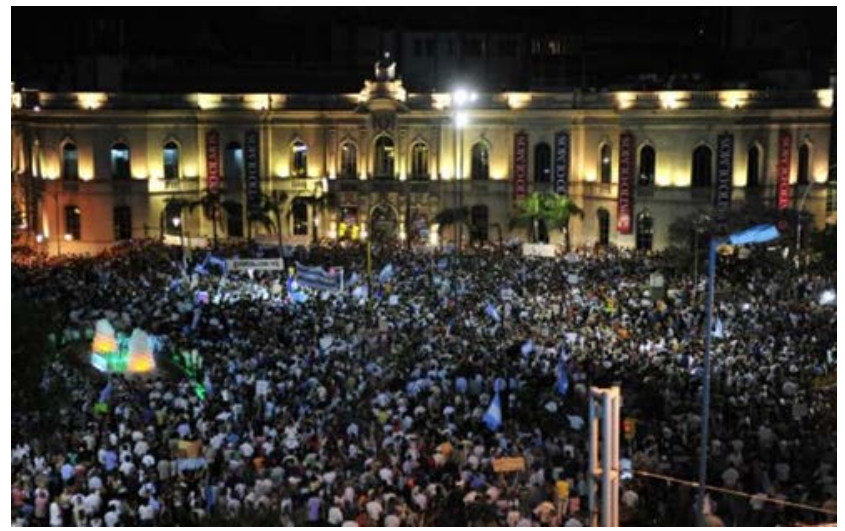

Figura 4. Expresión del movimiento indignados en Córdoba, Arg. Evento 15-O., octubre 2011. Fuente: Día a Día (2011)

Los casos esbozados a manera introductoria y contextual al ensayo, representan ejemplos concretos de como los espacios públicos se habrían tornado parte del espectáculo del consumo a partir de las estrategias comunicacionales del orden digital SIC, en particular por el uso de narrativas transmedia. Un consumo que no deviene en un producto manufacturado, sino por el contrario, un bien de consumo intangible que agencia identidades colectivas y regímenes escópicos urbanos, y que en términos bourdieuanos, se posibilitan como plataformas de sentido y de capital social de los sujetos. En tal sentido, la experiencia estética construida a partir de los dispositivos tecno-culturales TIC institucionalizarían los espacios públicos actuales a partir de una dimensión simbólica capaz de instrumentar sus aspectos físico-espaciales, legales y sociales. Esta dinámica convertiría el proscenio del que habla Delgado en un lugar de visibilización espectacularizado y vinculado a los procesos de construcción identitaria colectiva, un proceso simbólico que no solo respondería a la lógica de mercancía propiciada por la comunicación de imaginarios socio-urbanos, sino también a la dialéctica de los prosumidores en la co-producción y co-comunicación de los mismos, posibilitados por el acceso a las tecnologías digitales.

\section{HACIA FUTUROS DEBATES}

Los medios que de momento constituyen la instancia de sustitución de ese espacio publico planetario inexistente, están perpetuamente sometidos a la tentación de confundir espacio publico con espacio del público, en el sentido teatral del término. Ese público _vemos a veces que se intenta seducirlo y halagarlo, en lugar de informarlo_ a menudo es invitado a consumir pasivamente las noticias del mundo, como un espectáculo cinematográfico o una serie televisiva. (Augé, 2015: p.43)

El pensamiento de Marc Augé sintetiza de alguna manera las discusiones expresadas por este trabajo y que intentaron, como reza su objetivo principal, aportar al debate transdisciplinar dentro del urbanismo en torno a 
los debates que suscitan los espacios públicos y sus discusiones actuales dentro del orden digital de la SIC. En particular, aquellos referidos a la caracterización de los mecanismos de mercantilización del espacio y de sus vivencias, entendidas como experiencias estéticas, y resultado del acceso y consumo de tecnologías digitales y sus nuevas lógicas socio-económicas.

En este sentido, se han abierto discusiones acerca de nociones instrumentales del campo disciplinar del urbanismo como tiempo-espacio y limite, y otros abordajes que no suelen incorporase como categorías propias de análisis y que refieren tal vez al campo de las ciencias sociales o las humanidades. Ciertamente, el posicionamiento disciplinar de este ensayo representa una hibridación, una transdisciplinariedad que busca transversalizar la problemática desde nuevas miradas y campos.

Podemos sostener que considerar un enfoque disciplinar oblicuo sobre las problemáticas del hábitat contemporáneo, en particular acerca de los espacios públicos, constituiría una epistemología capaz de encuadrar y comprender la complejidad de los procesos socio-culturales actuales. Desde este posicionamiento, se intentó proponer una mirada crítica acerca de los espacios públicos, que posibilite generar un marco conceptual de referencia en función de repensarlo como concepto e idea. Particularmente, poder aportar a una comprensión holística y una mejor caracterización, como conjunto de relaciones y derechos sociales que hacen de nuestras ciudades un lugar más asequible frente a la complejidad de los fenómenos socio-urbanos descriptos al comienzo de este trabajo.

Para finalizar, problematizar los espacios públicos a partir del orden digital SIC representa un desafío epistémico y hasta disciplinar, ya que la consolidación de los dispositivos tecno-culturales TIC como instrumentos y generadores de una meta-realidad, a veces des-territorializada, sitúan a nuestra disciplina en un dilema ontológico, pero necesario, en función de (re)pensar nuestras categorías de análisis y con ellas una nueva disciplina de cara a los desafíos que el mundo informacional, la aldea global y el consumo digital nos impone con prisa.

Espacios públicos ¿Bienes de consumo? pretendió plantear interrogantes más que certezas. Buscó ser un punto de partida a futuros debates que visibilicen procesos culturales y espaciales que marcan una trayectoria que difícilmente sea modificada: la de una mayor injerencia de los dispositivos tecno-culturales TIC como intermediarios de una 'realidad' socio-urbana cada vez más difusa, pero al mismo tiempo, más intensa, compleja y desigual.

[...] El desafío actual de los arquitectos no es construir edificios más altos o nuevas ciudades, sino construir una nueva disciplina. La arquitectura es dependendiente de las condiciones del mundo y de la cultura, y no un arte autónomo. Ahora estamos muy ligados a la imagen del arquitecto-artista en su torre de marfil y yo pienso que eso se va a acabar. Viene una nueva disciplina. (Souto de Moura, 2015) 


\section{BIBLIOGRAFIA REFERENCIADA}

- Bauman, Z. (2013). Modernidad liquida. Buenos Aires: Fondo de la Cultura Económica

- Benjamín, W. (2003). La obra de arte en la época de la reproductividad técnica. México: Editorial Itaca

- Borja, J \& Castells, M. (1998). Local y Global, la gestión de las ciudades en la era de la información. Madrid: Taurus.

- Borja, J. (2014). Prologo. En Domínguez Moreno L. \& Sánchez Gonzales D. (Ed.) Identidad y espacio público. Ampliando ámbitos y prácticas. Barcelona: Gedisa.

- Castells, M. (1997). La era de la información, economía sociedad y cultura. Madrid: Alianza.

- (1998). La era de la información, el poder de la identidad. Madrid: Alianza.

- (2009). Comunicación y poder. Madrid: Alianza.

- Cortez Oviedo, S. (2018). Espacio públicos y TIC: el rol de la experiencia estética en sus usos y apropiaciones. Revista ALAS - Controversias y concurrencias latinoamericanas (México),16, 23-34.

- Debord, G. (1995). La sociedad del espectáculo. Buenos Aires: La marca editora.

- Delgado, M. (2015). El espacio público como ideología. Madrid: Catarata.

- Fernández. R. (2014). Seminario Teoría, crítica y gestión de la arquitectura, la ciudad y el territorio. Córdoba: FAUD-UNC.

- Finquelievich, S. (2000). Los actores sociales urbanos en la sociedad de la información: de los hippies al e-commerce. En: Repensando la experiencia urbana de América Latina: cuestiones, conceptos y valores: Buenos Aires: Clacso.

- (2016). I-Polis, ciudades en la era de internet. Buenos Aires: Diseño.

- Foucault, M. (1984). El juego de Michel Foucault. En: Saber y verdad. Madrid: Ediciones la Piqueta.

- García Fanlo (2011). ¿Qué es un dispositivo? Foucault, Deleuze, Agamben. Revista A parte Rei, revista de filosofía. $\mathrm{N}^{\circ} 74$. (España)

- Gravano, A. (2013). Antropología del urbano. Buenos Aires: UNICEN

- Habermas, J. (2005). Historia y critica de la opinión pública. Buenos Aires: Alianza

- Jay, M. (2003) Campos de fuerza. Entre la historia intelectual y la crítica cultural. "Regímenes escópicos de la modernidad". Buenos Aires: Paidós.

- Latour, B. (2007). Nunca fuimos modernos, ensayo sobre una antropología simétrica. Buenos Aires: Siglo XXI

- (2008). Reensablar lo social, una introducción a la teoría del actor red. Buenos Aires: Manantial

- Rancière, J. (2014). El reparto de lo sensible. Estética y política. Buenos Aires: Prometeo.

- Sennett, R. (2011). El declive del hombre público. Barcelona: Anagrama.

- Sontag, S. (2005), Sobre la fotografía. Bogotá: Editorial Alfaguara.

- Žižek, S. (1994). La Identidad y sus vicisitudes, la Lógica de la Esencia de Hegel como una teoría de la Ideología. Zizek en español. http://www.geocities.ws/zizekencastellano/artLaidentidad.html (Consulta, 25/02/2018) 